\title{
How to Get Things Done in Social Virtual Reality - A Study of Team Cohesion in Social Virtual Reality-Enabled Teams
}

\author{
Osku Torro \\ Tampere University \\ osku.torro@tuni.fi
}

\author{
Jani Holopainen \\ University of Helsinki \\ jani.m.holopainen@helsinki.fi
}

\author{
Henri Jalo \\ Tampere University \\ henri.jalo@tuni.fi
}

\author{
Henri Pirkkalainen \\ Tampere University \\ henri.pirkkalainen@tuni.fi
}

\author{
Antti Lähtevänoja \\ University of Jyväskylä \\ antti.lahtevanoja@helsinki.fi
}

\begin{abstract}
Social virtual reality (SVR) enables teams to operate in a virtual environment that simulates and enhances real-world interactions. However, there is an absence of empirical analysis of how SVR can affect the performance of virtual teams. This paper documents how SVR affects the formation of team cohesion (i.e., task cohesion and social cohesion), which is a critical success factor for team performance. To address this gap in the research, we conducted a qualitative study by interviewing 20 members from virtual teams assigned to perform a challenging collaborative task in SVR. As a contribution, our study identifies five primary affordances and 11 sub-affordances for team cohesion in SVR. We also found that team cohesion actualization was limited in the use of SVR environments of our study. However, we conclude that hindrances to team cohesion formation in SVR can be mitigated by focusing on the further development of material properties of SVR.
\end{abstract}

\section{Introduction}

Virtual reality (VR) is increasingly being used to simulate business-critical activities in organizations $[14,29]$. The development of VR technology has taken significant steps forward in the past couple of years and is now rapidly meeting the expectations researchers and practitioners placed on it over the decades. As one indication of this improvement, many of the world's biggest software companies, such as Microsoft, Facebook, and Apple, continue to make vast investments in VR technology [3, 10, 34]. VR market growth predictions also suggest that VR will have significant role to play in organizations. For instance, Grand View Research [9] expects VR revenues to grow from $\$ 12$ billion in 2020 to $\$ 72.8$ billion by 2024 .

Recent technical developments have enabled VR to support multi-user scenarios. The number of Social Virtual Reality (SVR) applications (i.e., a VR environment that is used as a communication platform) have increased rapidly in the last couple of years $[14,29]$. The use of SVR has the immediate potential to transform how organizations handle their remote-work practices, especially in terms of remote collaboration in knowledge-intensive work [29]. Prior studies have proposed that SVR can change remote work by enabling new methods of social interaction (e.g. $[1,12])$ and thus, has a promise to enhance or transform virtual team dynamics [24, 29].

Virtual teamwork is dependent on team cohesion, defined as "the shared bond/attraction that drives team members to stay together and to want to work together" [22, p. 365]. A body of empirical research highlights that team cohesion is critical for team performance, especially in situations that involve long-lasting collaboration on complex topics [22]. However, conventional remote-work tools struggle to create and maintain team cohesion, a fact that has become apparent during the COVID-19 pandemic [29]. It is likely that extensive remote working can cause drops in organizational productivity that are mainly due to decreases in innovation, creativity, and informal sociability [8]. Accordingly, some organizations are already looking into SVR to mitigate these problems (e.g., [7, 33]). However, to the best of our knowledge, no team level analysis of SVR use and its outcomes has been empirically examined in prior literature, which has mainly examined individuals' perceptions of social interactions (e.g., [7, 11, 15, 18, 
20, 31, 32]) and different forms of presence (e.g., [11, 24, 31]. Accordingly, the examination of team cohesion formation as a critical performance indicator for SVR enabled virtual teams has not been studied.

To address this research gap, we asked the following research question: How does SVR contribute to the formation of team cohesion in remote virtual teams? This issue is critical because it is important to know what factors contribute to the emergence of team cohesion in SVR and thus to the performance of SVRenabled virtual teams. To answer the research question, we carried out a qualitative study with a semi-structured interview approach to examine the study participants' opinions in depth. This approach enabled us to provide rich insights from previously unmapped connections between IT features and user perceptions [30].

As a theoretical contribution, we identify five primary and 11 sub-affordances for team cohesion formation in SVR. In our analysis, we also illustrate hindrances to team cohesion formation and their connection with the functional limitations of SVR's material properties. Identifying team cohesion affordances in SVR also enables researchers to study team dynamics and performance indicators in SVR. As a practical contribution, providing understanding on team cohesion formation in SVR helps system architects and developers further develop critical material properties of SVR that boost the performance of SVR-enabled teams.

The rest of the article is structured as follows. In Section 2, the theoretical background related to SVR, team cohesion, and affordances is examined. Next, the methodology of the study is described in Section 3. Following this, we present the empirical findings of our study. Lastly, the findings and contributions of the study are discussed, followed by the limitations of the study and some suggestions for future research.

\section{Theoretical background}

\subsection{Social virtual reality}

Social virtual reality refers to a VR environment that is used as a communication platform that includes different multi-user features, such as avatar-based interaction, shared space, and tools for remote collaboration [29]. The most studied attributes of SVR include forms of presence (e.g., co-presence, "being there with others"; [24, p. 438] and social interactions (e.g., [12]). Immersion and spatial interaction have been identified as contributing to the feeling of copresence [24], which is a critical difference between SVR and other multi-user virtual environments [29].
Holopainen et al. [11] found design principles to enhance sociability in VR environments. The study suggests that the outcomes of social interactions in SVR are, for example, improved co-creation and coinnovation. Another study with an explicit focus on SVR by Latoschik et al. [16] studied the relationship between avatar realism, embodiment, and social interactions. They found that more-realistic avatars contribute to feelings of embodiment and higher quality of social interactions. Many similar studies concerning SVR environments have been conducted (e.g., [7, 11, 15, 18, 20, 31, 32]). A common approach in these studies has been to examine individuals' perceptions of social interactions in SVR. However, there is a lack of studies examining team outcomes rather than individual perceptions. For this reason, this study focuses on SVR use and participant teams' shared experiences and outcomes, that is, team cohesion. Another reason to adopt team cohesion as an analytical framework is that it has strong empirical links to team performance [22].

\subsection{Team cohesion and affordances}

Team cohesion, which includes social- and taskcohesion elements, correlates strongly with team performance [22]. Task cohesion is "an attraction or bonding between group members that is based on a shared commitment to achieve the group's goals and objectives" [22, p. 368]. In addition, social cohesion has been defined as "a closeness and attraction within the group that is based on social relationships" [22, p. 368].

Achieving team cohesion in VR can be difficult. According to Dede et al. [6], VR environments must be designed especially carefully when the goal is to solve complex problems. In terms of the plan, act, reflect cycle, Dede et al. recognized that planning in VR is often difficult. Acting (i.e., learning-by-doing) works well, while reflecting tends to be difficult.

On the other hand, including elements of social interaction in VR can significantly improve its potential for the acquisition of skills and knowledge $[6,29]$. Furthermore, many scholars agree that VR has long been a promising tool for facilitating collaboration $[1,24]$ and the effects of embodiment and different forms of presence have been recognized to have the potential to affect group dynamics in virtual teams $[24,29]$. However, there is basically no research on SVR system or technology features that enable or enhance collaboration, and extant VR affordance research (e.g., [26]) has identified collaboration as merely one of the generalized affordances created by VR but has not studied this social aspect in depth. 
In the information systems (IS) literature, affordances have been used to explain the relationships between system features and their outcomes. Bernhard et al. [4] defined an affordance process as including affordance existence, perception, actualization, and outcomes. They defined affordance existence as the outputs of organizational strategies and technological features; that is, affordances exist as a result of these two main factors. Affordance perception is an individual process where previous experiences and perceptions play a major role. Furthermore, some existing affordances may be perceived and some not. The same applies to affordance actualization: Some perceived and recognized affordances are further actualized and some not. The last phase is the affordance outcomes, representing the meaningful results in terms of organizational, systemic, or individual goals. Strong et al. [28] suggest that there is a feedback loop from the affordance outcomes that reshapes organizational strategies, as well as technological features, and thus the affordance existence.

Furthermore, we draw from Markus and Silver [19] and describe the essential features of the technology as material properties. This analytical framing helps us provide a framework for how SVR's material properties can be used to enhance virtualteam performance. The framework combines the affordance process [4] as well as team cohesion elements [22] which are further categorized under primary- and sub-affordances (e.g., [26]), i.e., higher order abstractions and latent constructs.

\section{Method}

The objective of this study required data on how members of virtual teams experienced the formation of team cohesion in SVR. We chose to use a qualitative approach based on interview data to target the interviewees' experiences of using SVR. We used this approach because qualitative methods can provide rich and previously unmapped insights about the connections between IT features and user perceptions [30].

\subsection{Data collection}

The empirical data were collected from student teams working on a six-week knowledge work assignment. The assignment was part of a master's level university course about organizational teamwork. Each virtual team was assigned a challenging task in SVR to complete over a six-week period. To improve the transferability of the findings of our study into other contexts, the task was structured to meet the requirements of collaborative knowledge work (e.g., a need for open-ended problem solving and the mental alignment of participants). In their tasks, the teams focused on the organizational adoption and/or use of an emerging technology in a context of their own choosing. Teams used Oculus Quest headmounted displays in their meetings and experimented with multiple SVR platforms, such as Spatial, Immersal, Big Screen, Glue, AltspaceVR, and XR Campus (a large-scale collaborative SVR platform that was in an early alpha phase during data collection). From these options, each team selected Spatial as the main platform for their collaboration.

Twenty semi-structured interviews were conducted for the study between October 2020 and March 2021. The interviews lasted between 30 and 60 minutes. The interviewees were asked to reflect on their SVR user experiences and specifically to reflect on the potentials and bottlenecks, as well as their ability to use SVR in virtual teamwork. All interviews were held via video conferencing, and interviews were recorded and transcribed for later analysis. Data were collected by interviewing each member of the virtual teams (a total of six teams with three to four members each). All the interviewees were students in the age range of 21 to 30 . Twelve of the interviewees were women $(60 \%)$ and eight were men $(40 \%)$. Eighteen interviewees were Finns and two were French.

\subsection{Data analysis}

In this study, we analyzed individual users' perceptions and actions in terms of task and social cohesion formation in SVR. The analysis followed the affordance process framework [4] i.e., analysis of the affordance perceptions and actualizations. Perceptions that were not fully actualized allowed us to interpret hindrances which are our propositions to be solved by the future research and designs. All task and team cohesion affordances were categorized according to primary affordances and sub-affordances (e.g., [26]).

Our research approach can be considered as an interpretive case study [23]. In the process of qualitative and interpretive data analysis, we drew from Berg [3] and formed overarching categories from prior literature, created data-driven categories and coding schemes, searched for patterns, and reflected on the findings in the context of prior research. Initially, task cohesion and social cohesion were selected as the overarching categories for the analysis because of their strong empirical links with team performance [22]. Notes from the interviews were then assigned individual labels and grouped under the two aforementioned categories. We continuously 
ensured that the labels were compatible with the data and literature.

\section{Findings}

In this section, we present the qualitative findings of our study, distinguishing primary and subaffordances for task and social cohesion, which are critical components in team cohesion formation. We also describe how different hindrances prevent the actualization of these affordances in SVR. Our findings and examples from data are summarized in Tables 1 and 2 .

\subsection{Task cohesion}

\section{Shared sense-making}

Shared sense-making (i.e., the team's ability to understand and communicate task-related topics) was identified as one of the primary affordances for task cohesion formation in SVR. In addition, dialogue and information transfer were identified as subaffordances for shared sense-making.

The basic building block of dialogue was avatarbased interaction, including both verbal and nonverbal communication. In addition, shared space and spatial sound contributed to dialogue quality. When people presented task-related content in VR, 2D screens and $3 \mathrm{D}$ objects were also used in creating dialogues. In addition, material properties such as emojis and voicetalk indicators were perceived to enhance nonverbal communication, distinguishing the use of SVR from face-to-face communication. As one interviewee noted, "We did not talk over each other that much in VR. We could hear who was talking and where the sounds were coming from. We also used emojis in turn taking."

However, the lack of richness in nonverbal communication hindered dialogue because participants were not able to perceive each other's nonverbal cues in discussions. An inability to hold private or small-group discussion due to spatial limitations also decreased dialogue: "It would be nice to discuss with someone in private, or in a small group. Then you could continue discussing your own stuff without interrupting others or breaking your own chain of thoughts."

Another sub-affordance of shared sense-making was information transfer, where asynchronous communication (e.g., sticky notes), content persistence, as well as shared space as a living 3D document were perceived as useful properties; for example, "It was good that the environment was saved. We used the Lean Canvas model and PESTEL, and later were able to return to what had been done before."

However, an inefficient asynchronous communication pipeline (e.g., the inability to edit cloud documents) was seen as a hindrance to information transfer. In addition, a lack of task-related content decreased information transfer. Here, one interviewee expresses frustration at how difficult it was to get content into SVR and the potential thus lost: "I thought that sharing content would have been easier. There should be like 20 displays open [in VR], with all the information available."

\section{Shared focus}

Shared focus (i.e., the team's ability to focus on the task at hand) was perceived as one of the most fundamental benefits of using SVR in remote collaboration and was thus selected as a primary affordance of task cohesion formation in SVR. More specifically, task-related focus and co-presence were seen as important sub-affordances. In SVR, immersive spatial communication and interaction (in addition to the use of head-mounted displays that isolate users from the real world and other IT interferences) resulted in an increase in both task-related focus and co-presence. As one of the interviewees stated, "You could see another person's body [as an avatar] in the same room. You see the hands, and everything that represents the other person... It felt like everyone was $100 \%$ present."

Additionally, task-related focus was enhanced by material properties such as nonverbal communication (e.g., gaze and hand gestures) and tools or features that help focus attention (e.g., laser pointers). Shared space, avatar-based interaction, and status display features (e.g., mute) increased co-presence. However, difficulty in prioritizing or filtering task-related content was seen to decrease task-related focus.

There were also at least three hindrances that decreased co-presence: (1) chaotic or too-fast movement of other avatars, (2) difficulty tracking the location of other avatars in a shared environment, (3) difficulties in perceiving user status (e.g., offline).

\section{Shared workflows}

Shared workflow (i.e., the ability of the team to perform and coordinate tasks) was the last primary affordance identified under the affordances contributing to task cohesion. Role and task assignment was found to be a sub-affordance, with 
Table 1. Task cohesion affordances in SVR: affordance actualizations and hindrances

\begin{tabular}{|c|c|c|c|}
\hline \multicolumn{4}{|c|}{ Task cohesion } \\
\hline \multirow{2}{*}{$\begin{array}{l}\text { Primary } \\
\text { affordances }\end{array}$} & \multirow{2}{*}{$\begin{array}{l}\text { Sub- } \\
\text { affordances }\end{array}$} & \multicolumn{2}{|c|}{ Example from data } \\
\hline & & Affordance actualization & Hindrances \\
\hline \multirow[t]{2}{*}{$\begin{array}{l}\text { Shared } \\
\text { sense- } \\
\text { making }\end{array}$} & Dialogue & $\begin{array}{l}\text { "We watched documents together in } \\
\text { VR, and body language such as hand } \\
\text { movements was conveyed relatively } \\
\text { well. It felt almost like a face-to-face } \\
\text { meeting. VR is good if you have to } \\
\text { discuss technical issues, for example." } \\
\text { Interview } 10 \text {, male, } 28 \text { years old. }\end{array}$ & $\begin{array}{l}\text { The lack of richness in nonverbal } \\
\text { communication (decrease in dialogue): "It } \\
\text { [the lack of realistic avatar gaze] was } \\
\text { difficult when you couldn't target speech to } \\
\text { an individual rather than to a group." } \\
\text { Interview } 19 \text {, female, } 24 \text { years old. }\end{array}$ \\
\hline & $\begin{array}{l}\text { Information } \\
\text { transfer }\end{array}$ & $\begin{array}{l}\text { "When you turn your head, there can } \\
\text { be information anywhere. Old and new } \\
\text { content, such as notes, and screens, } \\
\text { were left to settle [in the virtual space]. } \\
\text { You could go and check that content } \\
\text { without disturbing others in the same } \\
\text { space." Interview 5, male, } 26 \text { years old. }\end{array}$ & $\begin{array}{l}\text { Inefficient asynchronous communication } \\
\text { pipeline (decrease in information transfer): } \\
\text { "After the meeting, we have to write the } \\
\text { documents separately outside VR." } \\
\text { Interview } 11 \text {, female, } 22 \text { years old. }\end{array}$ \\
\hline \multirow[t]{2}{*}{$\begin{array}{l}\text { Shared } \\
\text { focus }\end{array}$} & $\begin{array}{l}\text { Task-related } \\
\text { focus }\end{array}$ & $\begin{array}{l}\text { "We were forced to focus on a task at } \\
\text { hand because multitasking is difficult in } \\
\text { VR. In Teams one can do the dishes at } \\
\text { the same time!" Interview } 20 \text {, female, } \\
27 \text { years old. }\end{array}$ & $\begin{array}{l}\text { Difficulty prioritizing or filtering task-related } \\
\text { content (decrease in task-related focus): } \\
\text { "There should be a dedicated object that } \\
\text { would draw attention to a specific point. In } \\
\text { this way, one would be able to have more } \\
\text { controlled discussions." Interview 15, } \\
\text { female, } 23 \text { years old. }\end{array}$ \\
\hline & Co-presence & $\begin{array}{l}\text { "There was a feeling of group } \\
\text { cohesion. You can move, move around } \\
\text { with others, sit with others. There was } \\
\text { a much stronger feeling of working } \\
\text { together." Interview 13, male, } 21 \text { years } \\
\text { old. }\end{array}$ & $\begin{array}{l}\text { Difficulties perceiving user status } \\
\text { (decrease in co-presence): "There should } \\
\text { be an option available to indicate that you } \\
\text { are not currently available. Users were } \\
\text { jumping between VR and the real world, } \\
\text { which made things unclear." Interview } 7 \text {, } \\
\text { female, } 25 \text { years old. }\end{array}$ \\
\hline \multirow[t]{2}{*}{$\begin{array}{l}\text { Shared } \\
\text { workflows }\end{array}$} & $\begin{array}{l}\text { Role and } \\
\text { task } \\
\text { assignment }\end{array}$ & $\begin{array}{l}\text { "Setting up group roles, such as in } \\
\text { terms of retrieving and sharing } \\
\text { information, was easy because we } \\
\text { were in the same space. In Teams or } \\
\text { Zoom there's always someone who } \\
\text { shares the screen, in VR we just take } \\
\text { turns." Interview } 7 \text {, male, } 25 \text { years old. }\end{array}$ & $\begin{array}{l}\text { Difficulty sharing and assigning tasks } \\
\text { (decrease in role and task assignment): } \\
\text { "There should be ready-made tasks in VR, } \\
\text { so that we wouldn't have to spend time } \\
\text { writing them down in VR." Interview } 10 \text {, } \\
\text { male, } 29 \text { years old. }\end{array}$ \\
\hline & $\begin{array}{l}\text { Collaborative } \\
\text { work }\end{array}$ & $\begin{array}{l}\text { "We used sticky notes and drawing } \\
\text { features. It was easy to illustrate your } \\
\text { ideas while brainstorming. It was about } \\
\text { doing things together." Interview } 14 \text {, } \\
\text { female, } 22 \text { years old. }\end{array}$ & $\begin{array}{l}\text { Inefficient user input (decrease in } \\
\text { collaborative work): "Typing in VR was } \\
\text { really slow. Presentations and } \\
\text { conversations succeeded, but it was } \\
\text { difficult to create something new." } \\
\text { Interview } 6 \text {, female, } 23 \text { years old. }\end{array}$ \\
\hline
\end{tabular}

three advancing properties: conventional role and task assignment (e.g., user profiles connected to tasks), ecologically valid role and task assignment (e.g., a virtual presentation booth or sticky notes), and 
transparent task and project management systems (e.g., Kanban boards). In general, role assignment in SVR was perceived to be intuitive; for example, "In VR, someone just picked up the microphone, and his voice was amplified over others." However, difficulty sharing and assigning tasks was seen as a hindrance to role and task assignment.

Another sub-affordance was collaborative work, which was enhanced by shared space and collaboration tools (e.g., 2D screens, whiteboards, and sticky notes) and task-related interactions. As one interviewee described, "Drawing and explaining schemes and ideas to others worked well." However, inefficient user input was seen as a serious hindrance to collaborative work. All interviewees agreed that this hindered collaborative work considerably; for example, "Collaboration was really hard. When we had to write things down quickly, everything became really complicated." Other significant hindrances to collaborative work were inefficient workflows and content pipelines between VR and the real world, such as an inability to use a shared browser in VR.

\subsection{Social cohesion}

\section{Enhancing task relationships}

In terms of enhancing task relationships (i.e., social bonding through tasks), the first sub-affordance recognized was monitoring of user participation and performance, which many participants saw as a natural outcome of using SVR. Spatial collaboration and communication in a shared space (e.g., drawing on a whiteboard or small-group discussions) enabled participants to concretely perceive how others did their part and contributed to the performance of tasks. As one interviewee described, "It felt like talking to people, and being in the same place with them, and not just talking to a screen. You could see if everyone was involved."

Table 2. Social cohesion affordances in SVR: affordance actualizations and hindrances

\begin{tabular}{|c|c|c|c|}
\hline \multicolumn{4}{|c|}{ Social cohesion } \\
\hline \multirow{2}{*}{$\begin{array}{l}\text { Primary } \\
\text { affordances }\end{array}$} & \multirow{2}{*}{$\begin{array}{l}\text { Sub- } \\
\text { affordances }\end{array}$} & \multicolumn{2}{|c|}{ Example from data } \\
\hline & & Affordance actualization & Hindrances \\
\hline \multirow[t]{2}{*}{$\begin{array}{l}\text { Enhancing } \\
\text { task } \\
\text { relationships }\end{array}$} & $\begin{array}{l}\text { Monitoring of } \\
\text { user } \\
\text { participation } \\
\text { and } \\
\text { performance }\end{array}$ & $\begin{array}{l}\text { "In VR, you can see if someone is } \\
\text { holding a phone. You can see how they } \\
\text { are participating and contributing." } \\
\text { Interview } 17 \text {, male, } 24 \text { years old. }\end{array}$ & $\begin{array}{l}\text { Inefficient and non-transparent } \\
\text { workflows (decrease in monitoring of } \\
\text { user participation and performance): } \\
\text { "The lack of transparency was a } \\
\text { problem. There [in a virtual space] } \\
\text { should be an old-fashioned project } \\
\text { room, and an ability to print [task } \\
\text { related content] to the walls. When } \\
\text { everything would be visually there, it } \\
\text { would be clearer." Interview 10, male, } \\
28 \text { years old. }\end{array}$ \\
\hline & Reciprocity & $\begin{array}{l}\text { "It [working together in VR] was more } \\
\text { motivating than in Teams. This was an } \\
\text { especially positive thing when there } \\
\text { was a new person in the group. I also } \\
\text { discussed more with others in VR that I } \\
\text { would normally do in Teams." Interview } \\
8, \text { female, } 24 \text { years old. }\end{array}$ & $\begin{array}{l}\text { Inefficient and non-transparent } \\
\text { workflows (decrease in reciprocity): } \\
\text { "There were no tools in VR. There } \\
\text { should be a VR desktop that can be } \\
\text { shared with others, to share a code, pair } \\
\text { encoding, for example, so I could show } \\
\text { others that I was doing this kind of } \\
\text { function." Interview 7, male participant, } \\
25 \text { years old. }\end{array}$ \\
\hline $\begin{array}{l}\text { Enhancing } \\
\text { social } \\
\text { relationships }\end{array}$ & $\begin{array}{l}\text { Individuating } \\
\text { information }\end{array}$ & $\begin{array}{l}\text { "Being able to customize your avatar } \\
\text { was important in order to recognize } \\
\text { team members." Interview 1, male, } 25 \\
\text { years old. }\end{array}$ & $\begin{array}{l}\text { The lack of informative avatar profiles } \\
\text { (decrease in individuating information): } \\
\text { "Should you introduce yourself or stay } \\
\text { still? [Via avatar profiles] you could see } \\
\text { who is who. Being able to connect [real } \\
\text { persons and avatars] would make }\end{array}$ \\
\hline
\end{tabular}




\begin{tabular}{|c|c|c|}
\hline & & $\begin{array}{l}\text { things easier." Interview 15, female } \\
\text { participant, } 23 \text { years old. }\end{array}$ \\
\hline $\begin{array}{l}\text { Emotional } \\
\text { communication }\end{array}$ & $\begin{array}{l}\text { "Recognizing the avatar's facial } \\
\text { expressions was important even though } \\
\text { the mouth and eyes were faked to } \\
\text { move according to the user's real } \\
\text { movements." Interview } 1 \text {, male, } 25 \\
\text { years old. }\end{array}$ & $\begin{array}{l}\text { The lack of richness in nonverbal } \\
\text { communication (decrease in emotional } \\
\text { communication): "Now you cannot see } \\
\text { how the other user actually feels. You } \\
\text { can blame the technology, go hiding, } \\
\text { and claim that there was a poor } \\
\text { connection. Better avatars would help a } \\
\text { lot." Interview 11, female, } 22 \text { years old. }\end{array}$ \\
\hline $\begin{array}{l}\text { Informality and } \\
\text { playfulness }\end{array}$ & $\begin{array}{l}\text { "We took some pictures and videos } \\
\text { from the Web, laughed together, and } \\
\text { noticed that the group did well and was } \\
\text { comfortable being together." Interview } \\
1 \text {, male. } 25 \text { years old. }\end{array}$ & $\begin{array}{l}\text { The lack of informal content and } \\
\text { interactions (decrease in informality and } \\
\text { playfulness): "Gamified [informal] } \\
\text { content would allow people to get to } \\
\text { know each other and be more relaxed." } \\
\text { Interview 19, female, } 24 \text { years old. }\end{array}$ \\
\hline
\end{tabular}

The second sub-affordance was reciprocity (i.e., focusing on the reciprocal performance of tasks and an ability to provide help and feedback). For example, mechanisms for feedback such as gestures and emojis were seen beneficial for this sub-affordance. However, significant hindrances for both sub-affordances (monitoring of user participation and performance and reciprocity) included inefficient and non-transparent workflows.

\section{Enhancing social relationships}

Enhancing social relationships (i.e., social bonding through sociability) was recognized as a second primary affordance of social cohesion. Three subaffordances were identified: individuating information, emotional communication, and informality and playfulness. Avatar customization enhanced individuating information when participants were able to customize avatars based on their preferences or real-life appearance (e.g., cartoonish avatars built from photos). The lack of realistic facial information showed a decrease in individuating information but also, interestingly, had a positive effect on sociability for one participant: "It felt relieving to note that no one knew who you really were or what you looked like." The lack of individuating information in avatar profiles (e.g., showing users' organizational position) also hindered individuating information, emotional communication, and informality and playfulness.

Another sub-affordance was emotional communication, which was enhanced by the increase in an avatar's behavioral realism (e.g., gestures), or enhancements in nonverbal communication (e.g., gestures with sound and visual effects). However, the lack of richness in nonverbal communication was a hindrance in emotional communication as participants were not able to accurately perceive and predict each other's emotional states in SVR. Avatar's accurate behavioral realism (e.g., gaze and facial expressions) was one of the most important material properties of SVR that the participants missed the most in terms of creating social cohesion.

The last sub-affordance was named informality and playfulness, which was enhanced with material properties such as games and interactivity, avatar customization (e.g., non-human or otherwise transformed avatars), shared informal content (e.g., video wall), and customizable environment. The following quote is illustrative with respect to how many interviewees enjoyed each other's company in SVR: "The conversation got sidetracked... Someone found a cat, and soon we had six cats and a campfire. But this was welcome, because there hadn't been much contact between team members [during COVID-19], and now we were able to act like clowns. This kind of stuff increases team bonding." However, the lack of informal content and interactions led to a decrease in informality and playfulness, as opportunities for informal socialization were limited.

\section{Discussion}

The present study contributes to the scarce SVR literature, which has so far mainly focused on individual perceptions of social interactions (e.g., [7, $11,15,18,20,31,32])$ and different forms of presence (e.g., [11, 24, 31]. Although the use of SVR in enterprises is growing [28,14], there is currently a lack of research systematically focusing on team cohesion 
or other performance indicators of SVR-enabled teams.

Solving complex problems in VR has often been challenging [6], but the potential for increasing team performance with VR has also been noted in the literature $[24,28]$. However, the relationship between certain material properties of SVR and social interaction, as well as team cohesion outcomes, i.e., affordances, have not been systematically researched. This formed the basis of the motivation and analytical framework for this study's research question: How does SVR contribute to the formation of team cohesion in remote virtual teams?

In our analysis, we identified five primary affordances and $11 \mathrm{sub}$-affordances for team cohesion in SVR (Tables 1 and 2). We also found that the SVR environments in our study did not enable the full actualization of team cohesion affordances, and the root cause for these hindrances was found in the functional limitations of SVR's material properties.

However, more efficient material properties in SVR are constantly being introduced, and recent examples from industry show that SVR can already facilitate effective teamwork. For example, some of the newest SVR applications can now effortlessly tap into outside workflows (e.g., annotations made on 3D models in SVR can be transferred into related 2D design software) [13]. Hardware advancements in head-mounted displays (e.g., accurate eye tracking in the HP Reverb G2 and Varjo XR-3) are also increasing the behavioral realism of avatars in SVR, which can help more fully actualize some of the sub-affordances identified in our study, such as dialogue, task-related focus, and emotional communication. Furthermore, major industry players are investing heavily in increasing avatars' visual realism [5]. See-through keyboards (i.e., ability to see and use a physical keyboard in VR) are also starting to become available, increasing the input options for users [27].

These examples show that mitigating the hindrances of team cohesion formation in SVR and, ultimately, getting things done in SVR can be achieved by focusing on the development of critical material properties of SVR. Through these developments, we believe that SVR can further redefine conventional online collaboration practices in organizations. Based on the findings of our paper, we argue that SVR enables new methods of problem solving, increases task-related focus, and improves social relations that, interestingly, are all well-known bottlenecks in highperforming remote work.

\subsection{Research and practical contributions}

Studying affordances for team cohesion (i.e., task and social cohesion) enabled us to study team performance indicators in SVR-enabled virtual teams. By identifying five primary and 11 sub-affordances for team cohesion and illustrating the connection between hindrances to team cohesion formation and functional limitations of the material properties of SVR, our study provides a theoretical framework for IS research, focusing on team dynamics and performance in SVR. This is important because our study also improves the understanding of SVR as a novel sociotechnical system that enables organizations to revamp their (often inefficient) remote work practices.

As a practical contribution, one of the main takeaways of our paper is that SVR enables unique mechanisms for team cohesion formation, but there are still many hindrances that prevent this from happening. Understanding team cohesion formation in SVR helps organizations further develop critical material properties of SVR that can boost the performance of virtual teams and lead to productivity gains in remote work. We also believe that our study has vast implications for many organizations using SVR across different fields, such as in education and business.

\subsection{Limitations and future topics}

One of the aims of this study is to provide a basis for identifying critical material properties for team cohesion formation in SVR, which we did not systematically conduct due to the scope of the study. Another limitation in our study was the limited amount of SVR platforms tested. Furthermore, the interview sample (students, mostly Finns) might emphasize affordances and experience team cohesion formation differently than if the sample were drawn from other countries or segments of the population. The transferability of our findings into the context knowledge work and virtual teams would also benefit from longitudinal data from authentic SVR use in virtual teams. As our subjective and interpretive analysis is prone to bias, team cohesion formation could also be measured quantitatively. However, as the features of the SVR environment can be strictly controlled, the potential for rigorous experiments examining how certain features and material properties of SVR affect team cohesion formation in SVR hold much promise. 


\section{Conclusion}

This study found that SVR has novel affordances for team cohesion, but their actualization was limited. However, our analysis suggests that further development of the material properties of SVR can significantly improve team cohesion formation in SVR. When more efficiently functioning material properties of SVR are introduced, and affordances for team cohesion will be more fully actualized, SVR's potential to facilitate virtual teamwork is significantly increased.

\section{Acknowledgements}

This research was co-funded by ECIU University project (612521-EPP-1-2019-1-NL-EPPKA2-EURUNIV), European Universities funding.

\section{References}

[1] Bailenson, J. N., Beall, A. C., Loomis, J., Blascovich, J., \& Turk, M. (2004). Transformed social interaction: Decoupling representation from behavior and form in collaborative virtual environments. Presence: Teleoperators \& Virtual Environments, 13(4), 428441.

[2] Bass, D. (2021). Microsoft steps up push to bring virtual reality to the masses. Bloomberg. https://www.bloomberg.com/news/articles/2021-03$02 /$ microsoft-steps-up-push-to-bring-virtual-realityto-the-masses [accessed 2021-2-6]

[3] Berg, B.L. (2004). Qualitative research methods for the social sciences. Boston, MA: Pearson Education.

[4] Bernhard, E., Recker, J., \& Burton-Jones, A. (2013). Understanding the actualization of affordances: A study in the process modeling context, ICIS 2013 proceedings.

[5] Brown, S. (2021). Facebook VR venture could include realistic avatars, Zuckerberg says. CNET. https://www.cnet.com/news/facebook-vr-venturecould-include-realistic-avatars-zuckerberg-says/ [accessed 2021-4-6]

[6] Dede, C. J., Jacobson, J., \& Richards, J. (2017). In Virtual, augmented, and mixed realities in education (pp. 1-16). Springer, Singapore.

[7] Fairs, M. (2020). Dezeen. https://www.dezeen.com/2020/05/13/incrediblevirtual-reality-coronavirus/ [accessed 2021-2-6]
[8] Gorlick, A. (2020). Stanford News. The productivity pitfalls of working from home in the age of COVID19. https://news.stanford.edu/2020/03/30/productivitypitfalls-working-home-age-covid-19/ [accessed 20213-4]

[9] Grand View Research (2021). Virtual reality market size, share \& trends analysis report by technology (semi \& fully immersive, non-immersive), by device (hmd, gtd), by component (hardware, software), by application, and segment forecasts, 2021-2028. Grand view research https://www.grandviewresearch.com/industryanalysis/virtual-reality-vr-market [accessed 2021-9-6]

[10] Gurman, M. (2021). Apple's first headset to be niche precursor to eventual AR glasses. Bloomberg. https://www.bloomberg.com/news/articles/2021-0121/apple-s-first-vr-headset-to-be-niche-precursor-toeventual-ar-glasses [accessed 2021-9-6]

[11] Heidicker, P., Langbehn, E., \& Steinicke, F. (2017). Influence of avatar appearance on presence in social VR. Paper presented at the 2017 IEEE Symposium on $3 D$ User Interfaces, 3DUI 2017-Proceedings, 233234. https://doi.org/10.1109/3DUI.2017.7893357

[12] Holopainen, J., Mattila, O., Parvinen, P., Pöyry, E., \& Tuunanen, T. (2021). Sociability in virtual reality: Evaluations of three iterative application versions along a design science research process. ACM Transactions on Social Computing, 4(1), 1-21.

[13] Horwitz, J. (2020). InsiteVR lets enterprise teams share complex 3D models on Oculus Quest. VentureBeat. https://venturebeat.com/2020/06/09/insitevr-letsenterprise-teams-share-complex-3d-models-onoculus-quest/ [accessed 2021-6-5]

[14] Jalo, H., Pirkkalainen, H., Torro, O., Lounakoski, M., \& Puhto, J. (2020, June). Enabling factors of social virtual reality diffusion in organizations. In Proceedings of the 28th European Conference on Information Systems (ECIS): An Online AIS Conference (pp. 1-15). in Proceedings of the 28th European Conference on Information Systems (ECIS).

[15] Latoschik, M. E., Kern, F., Stauffert, J., Bartl, A., Botsch, M., \& Lugrin, J. (2019). Not alone here?! Scalability and user experience of embodied ambient crowds in distributed social virtual reality. IEEE Transactions on Visualization and Computer Graphics, 25(5), 2134-2144. http://doi.org/10.1109/TVCG.2019.2899250

[16] Latoschik, M. E., Roth, D., Gall, D., Achenbach, J., Waltemate, T., \& Botsch, M. (2017). The effect of avatar realism in immersive social virtual realities. Paper presented at the proceedings of the ACM 
symposium on virtual reality software and technology, VRST, F131944.

http://doi.org/10.1145/3139131.3139156

[17] Liszio, S., \& Masuch, M. (2016, September). Designing shared virtual reality gaming experiences in local multi-platform games. In International Conference on Entertainment Computing (pp. 235240). Springer, Cham. http://doi.org/10.1007/978-3319-46100-7_23

[18] Maloney, D., Freeman, G., \& Wohn, D. Y. (2020). "Talking without a voice": Understanding non-verbal communication in social virtual reality. Proceedings of the ACM on Human-Computer Interaction, 4(CSCW2), 1-25.

[19] Markus, M. L., \& Silver, M. S. (2008). A foundation for the study of IT effects: A new look at DeSanctis and Poole's concepts of structural features and spirit. Journal of the Association for Information systems, 9(10), 5.

[20] Moustafa, F., \& Steed, A. (2018). A longitudinal study of small group interaction in social virtual reality. Paper presented at the Proceedings of the ACM Symposium on Virtual Reality Software and Technology,

VRST. http://doi.org/10.1145/3281505.3281527

[21] Mütterlein, J., Jelsch, S., \& Hess, T. (2018). Specifics of collaboration in virtual reality: How immersion drives the specifics of collaboration in virtual reality. PACIS 2018 Proceedings, 318.

[22] Salas, E., Grossman, R., Hughes, A. M., \& Coultas, C. W. (2015). Measuring team cohesion: Observations from the science. Human factors, 57(3), 365-374.

[23] Sarker, S., Xiao, X., Beaulieu, T., \& Lee, A. S. (2018). Learning from first-generation qualitative approaches in the IS discipline: An evolutionary view and some implications for authors and evaluators (PART 1/2). Journal of the Association for Information Systems, 19(8), 1.

[24] Schultze, U. (2010). Embodiment and presence in virtual worlds: A review. Journal of Information Technology, 25(4), 434-449.

[25] Slater, M., \& Sanchez-Vives, M. V. (2016). Enhancing our lives with immersive virtual reality. Frontiers Robotics AI, 3, 1-47. https://doi.org/10.3389/frobt.2016.00074

[26] Steffen, J. H., Gaskin, J. E., Meservy, T. O., Jenkins, J. L., \& Wolman, I. (2019). Framework of affordances for virtual reality and augmented reality. Journal of Management Information Systems, 36(3), 683-729.
[27] Stein, S. (2021). Typing in VR: How to connect a keyboard to your Oculus Quest 2. CNET. https://www.cnet.com/how-to/typing-in-vr-how-toconnect-a-keyboard-to-your-oculus-quest-2-and-howit-works/ [accessed 2021-6-4]

[28] Strong, D. M., Volkoff, O., Johnson, S. A., Pelletier, L. R., Tulu, B., Bar-On, I., Trudel, J., \& Garber, L. (2014). A theory of organization: EHR affordance actualization. Journal of the Association for Information Systems, 15(2), 2.

[29] Torro, O., Jalo, H., \& Pirkkalainen, H. (2021, in press). Six reasons why virtual reality is a game-changing computing and communication platform for organizations. Communications of the ACM.

[30] Venkatesh, V., Brown, S. A., \& Bala, H. (2013). Bridging the qualitative-quantitative divide: Guidelines for conducting mixed methods research in information systems. MIS quarterly, 21-54.

[31] Waltemate, T., Gall, D., Roth, D., Botsch, M., \& Latoschik, M. E. (2018). The impact of avatar personalization and immersion on virtual body ownership, presence, and emotional response. IEEE Transactions on Visualization and Computer Graphics, 24(4), 1643-1652. http://doi.org/10.1109/TVCG.2018.2794629

[32] Wang, L., Jiao, L., He, T., Li, J., \& Mühlhäuser, M. (2018, April). Service entity placement for social virtual reality applications in edge computing. In IEEE INFOCOM 2018-IEEE Conference on Computer Communications (pp. 468-476). IEEE.

[33] Warnke, J. (2020). Accenture. https://www.accenture.com/us-en/blogs/howaccenture-does-it/are-you-ready-for-closeencounters-of-the-virtual-kind [accessed 2021-3-4]

[34] Warrier, M. (2021). Facebook has dedicated about $20 \%$ of its workforce to VR/AR efforts: Report. Yahoo. https://finance.yahoo.com/news/facebookdedicated-20-workforce-vr-102220393.html [accessed 2021-6-6] 